\title{
ARGVMENTVM VOLVMINIS SECVNDI
}

\section{COMPENDIA}

1. Auctores . . . . . . . . . . . . . . IX

2. Tituli librorum. . . . . . . . . . . . XIX

3. Abbreviationes ceterae minus usitatae . . . . . . XXX

4. Sigla librorum manuscriptorum . . . . . . . . . . .XXXI

5. Nomina virorum doctorum selecta . . . . . . . . XXXIII

\section{SCHOLIA GRAECA}

ad Iliadis librum E . . . . . . . . . . . . . . . . . . 1 ad Iliadis librum $Z$. . . . . . . . . . . . . . 123 ad Iliadis librum $\mathrm{H}$. . . . . . . . . . . . . . . 222 ad Iliadis librum $\Theta$. . . . . . . . . . . . . . . 297 ad Iliadis librum I . . . . . . . . . . . . . . 447

In volumine primo corrigenda . . . . . . . . . . 547 Huic volumini addenda . . . . . . . . . . . . 549 
